\title{
Vaginal Discharge, CTCAE
}

National Cancer Institute

\section{Source}

National Cancer Institute. Vaginal Discharge, CT CAE. NCI Thesaurus. Code C143922.

A disorder characterized by vaginal secretions. Mucus produced by the cervical glands is discharged from the vagina naturally, especially during the childbearing years. 